\title{
APRENDIZAGEM AO LONGO DA VIDA: O “APRENDER A APRENDER" NA (RE)PRODUÇÃO DO CAPITAL LIFELONG LEARNING: “LEARNING TO LEARN” IN CAPITAL (RE)PRODUCTION
}

\author{
Gislei José Scapin 5 \\ Gilmar Belitz Pereira Junior 6 \\ Leandra Costa da Costa7
}

\section{RESUMO}

Este trabalho aborda a temática da aprendizagem ao longo da vida realizando uma análiseda Pedagogia do "aprender a aprender". Objetivamos compreender como o processo de aprendizagem, vinculada a lógica do "aprender a aprender", está sendo desenvolvido na escola pública brasileira como caminho para a (re) produção do capital. Metodologicamente segue uma abordagem qualitativa do tipo bibliográfica pautada pela filosofia marxista, organizado em dois momentos para entendermos a lógica do "aprender a aprender" em sua atual versão e sua materialização no contexto da escola pública via políticas e reformas educacionais. Por fim, ponderamos que esse processo forma trabalhadores em nível superficial e limitado de conhecimento,tratados como instrumento para (re)produzir o capital.

Palavras-chave: Educação. Aprendizagem. Capitalismo.

\begin{abstract}
This work deals with the theme of lifelong learning by analysing the Pedagogy of "learning to learn". We aim to understand how the learning, linked to the logic of "learning to learn", is being used in the Brazilian public school as a way of capital (re)production. Methodologically follows a qualitative approach of the bibliographic type guided by Marxist philosophy, organized in two moments to understand the logic of "learning to learn" in its current version and how it materializes in the context of public school through policies and educational reforms. Finally, we consider that this process corroborates to train workers in a superficial and limited level of knowledge, treated as an instrument to (re) produce capital.
\end{abstract}

Keywords: Education. Learning. Capitalism.

5 Especialista em Educação Física Escolar - Centro de Educação Física e Desportos/Universidade Federal de Santa Maria, Acadêmico do Curso de Pedagogia - Centro de Educação/Universidade Federal de Santa Maria e Mestrando em Educação Física - Linha de pesquisa Sócio-Cultural e Pedagógica da Educação Física - Centro de Educação Física e Desportos/Universidade Federal de Santa Maria, Rio Grande do Sul/ Brasil. E-mail: gjscapin@gmail.com

6 Bacharel em Educação Física e Especializando em Educação Física Escolar -pela Universidade Federal de Santa Maria, Rio Grande do Sul/ Brasil. E-mail: gilmarbelitz@gmail.com

7 Doutora em Educação - Linha de Educação Especial - pela Universidade Federal de Santa Maria. Professora do Departamento de Desportos Individuais da Universidade Federal de Santa Maria, Rio Grande do Sul/ Brasil. E-mail: Icostadacosta@ hotmail.com 


\section{INTRODUÇÃO}

Iniciamos este trabalho realizando a exposição de algumas palavras do estupendo filósofo e escritor Mario Sergio Cortella, que em sua bela obra "Não nascemos prontos! Provocações Filosóficas", nos alerta de algo importantíssimo para pensarmos e refletirmos nossa existência humana. O referido autor - caminhando no terreno da filosofia - profere as seguintes palavras:"É fundamental não nascermos sabendo e nem prontos; o ser que nasce sabendo não terá novidades, só reiterações." e segue: "Nascer sabendo é uma limitação porque obriga a apenas repetir e, nunca, a criar, inovar, refazer, modificar" (Cortella, 2015, p. 13).

Na concepção do autor supracitado, o ser humano é uma espécie que não nasce acabada/concluída, mas está em constante construção, ou seja, "vai se fazendo" (idem, p. 14). É no movimento das mudanças históricas e sociais que o ser humano projeta sua constituição em sua forma mais evoluída/complexa, constrói-se enquanto indivíduo inacabado/incompleto em um tempo-espaço que percorre toda sua trajetória terrena.

Na mesma linha do raciocínio de Cortella, outro autor - também da área da filosofia e da história -, seguindo outra corrente epistemológica, elucida que "o homem não se faz homem naturalmente; ele não nasce sabendo ser homem, vale dizer, ele não nasce sabendo sentir, pensar, avaliar, agir. Para saber pensar e sentir; para saber querer, agir ou avaliar é preciso aprender, o que implica o trabalho educativo" (Saviani, 2013a, p. 7).

Os autores dialogam entre si na perspectiva de que o ser humano'aprende' a'ser' humano, sendo o trabalho educativo uma categoria central para o processo de humanização dos sujeitos. Saviani (2013a, p. 13) esclarece que o"trabalho educativo é o ato de produzir, direta e intencionalmente, em cada individuo singular, a humanidade que é produzida histórica e coletivamente pelo conjunto dos homens", ou seja, o ser humano se humaniza na capacidade de produzir e socializar entre seus pares o que é produzido no movimento histórico, na relação entre os sujeitos e a natureza, na capacidade de produzir cultura e elaborar a natureza humana.

Toda a produção cultural e da natureza humana, que si imbricam com a natureza biofísica, constituem um acervo de conhecimentos e saberes indispensáveis para a sobrevivência da espécie. Para que os humanos sigam se reproduzindo, portanto, é fundamental que os saberes elaborados sejam transmitidos e socializados às gerações sucessoras, como forma de conceder continuidade a história da humanidade.

Percebemos que na produção da existência da humanidade, o'aprender'é essencial. É necessário aprender e se apropriar da natureza humana que é gerada pelo conjunto dos homens e mulheres na intenção de sobreviver e continuar concebendo a espécie. Como forma de proporcionar a aprendizagem da natureza humana/cultural - manifestação/movimento na qual o trabalho educativo se efetiva - a sociedade foi elaborando formas de socialização dos saberes, as quais foram sendo institucionalizadas e denominadas de 'escola', sendo a forma dominante de educação (Saviani, 2013a).

Com o avanço da complexidade das sociedades no decorrer da história, as escolas foram se tornando cada vez mais necessárias. Seus espaços estavam servindo para transmitir há um número cada vez maior de educandos o conhecimento produzido pela humanidade. Formas de transmissão de conhecimento foram sendo elaboradas para atingir os objetivos traçados para a educação/escolarização das novas gerações. Porém, com o desenvolvimento e mudanças nas estruturas sociais, com a modernização da sociedade em sua estrutura capitalista, o processo de escolarização foi percorrendo outros caminhos, assumindo outros objetivos e interesses, onde acabou sendo usado como meio para (re)produção da ordem social vigente (Frigotto, 2010).

Utilizamos como ponto de partida esta breve contextualização sobre a produção da existência humana, da educação e do aprender - como determinante para reprodução e sobrevivência da espécie - paratraçarmos um caminho de compreensão do processo de desenvolvimento e aprendizagem humana como instrumento para seguir com o modo de reprodução capitalista. A saber, objetivamos compreender como o processo de aprendizagem - que percorre por toda a vida dos sujeitos -, vinculada a lógica do "aprender a aprender", está sendo utilizada na escola pública brasileira como caminho para a (re)produção do capital.

Para tanto, traçamos um caminho metodológico de investigação bibliográfica a luz da abordagem filosófica marxista, pautada pelo Materialismo Histórico - Dialético, pois para a produção de conhecimento, nesta vertente teórica, consideramos a historicidade dos processos sociais e dos conceitos, bem como as condições socioeconômicas de produção e as contradições que emergem das práticas sociais. Por fim, com o método dialético analisamos a realidade de forma dinâmica e totalizante (Gil, 2008). 
Organizamos nosso trabalho em dois momentos. Primeiro elucidamos a pedagogia do "aprender a aprender" na estrutura capitalista e na lógica neoliberal. E, segundo, apresentamos as políticas educacionais e como estas formam o conhecimento e a escola pública para (re)produção do capital. Nosso trabalho pauta-se pela perspectiva da aprendizagem ao longo da vida, realizando uma análise de cunho teórico da pedagogia do "aprender a aprender" e seu uso no processo de socialização dos saberes no interior da escola pública como forma de dar prosseguimento a ordem social estabelecida pelo capital.

\section{“APRENDER A APRENDER" PARA (RE)PRODUZIR O CAPITAL}

Neste item, nos debruçaremos em elucidar como a Pedagogia do "aprender a aprender" está se manifestando no ambiente escolar brasileiro, consolidando um modelo de formação básica que segue a lógica do modo de produção capitalista, em sua conjuntura neoliberal, sendo utilizado como instrumento para (re) produção do capital e mantenedor do statusquo da sociedade.

Para traçarmos um movimento da aparência à essência do fenômeno, compreendendo-o em sua totalidade, torna-se necessário percorrermos um caminho histórico e dialético. Para compreendermos como a pedagogia do "aprender a aprender" se manifesta atualmente nas escolas públicas brasileiras, precisamos rememorar o caminho de constituição histórica que este modelo pedagógico percorreu até apresentar-se em sua forma mais complexa e atual.

Como ponto de partida, datamos o final do século XIX. Este período se constitui por rigorosas críticas ao, até então, inadequado modelo de Escola Tradicional. Acreditando na credibilidade da escola e em sua primordial função de equalização social, surge a pedagogia nova. Nesta nova perspectiva educacional, havia uma preocupação com o'rejeitado', ou seja, aqueles sujeitos que eram desajustados e inadaptados ao modelo educacional anterior. A educação, portanto, resolveria o problema da marginalidade, isto é, daqueles que estavam à margem da sociedade e da educação/escolarização, na medida em que cumprissem a função de ajustar e adaptar os indivíduos à sociedade, num aspecto de aceitação das diferenças e respeito à individualidade específica de cada um (Saviani, 2012).

A dimensão pedagógica estava direcionada para o "aprender a aprender" e a escola pública passou a ser referenciada de Escola Nova. Este novo modelo educacional configurou-se da seguinte forma:

[...] a organização escolar teria de passar por uma reformulação. Assim, em lugar de classes confiadas a professores que dominavam as grandes áreas do conhecimento, revelando-se capazes de colocar os alunos em contato com os grandes textos que eram tomados como modelos a serem imitados e progressivamente assimilados pelos alunos, a escola deveria agrupar os alunos segundo áreas de interesse decorrente de sua atividade livre. O professor agiria como um estimulador e orientador da aprendizagem cuja iniciativa principal caberia aos próprios alunos. Tal aprendizagem seria uma decorrência espontânea do ambiente estimulante e da relação viva que se estabeleceria entre os alunos e entre estes e o professor. [...]. Em suma, a feição das escolas mudaria seu aspecto sombrio, disciplinado, silencioso e de paredes opacas, assumindo um ar alegre, movimentado, barulhento e multicolorido. (Idem, p. 9)

Este modelo de escola proporcionava aos educandos certa autonomia pedagógica, descentralizando o processo de ensino-aprendizagem atribuído ao professor. Entretanto, em virtude das despesas geradas pelas demandas educacionais e pelo rebaixamento do nível de ensino - devido a despreocupação com o ensino por parte dos professores, fruto de uma má interpretação dos princípios pedagógicos - o modelo educacional da Escola Nova e da pedagogia do "aprender a aprender" não alterou o panorama do sistema escolar, agravando o cenário da marginalidade.

Embora o modelo educacional supracitado não tenha se efetivado naquele momento histórico-social ${ }^{8}$, sua fundamentação conceitual requer algumas observações. Ao entendermos o processo de aprendizagem ao longo da vida, ponderamos que a necessidade de aprender e apropriar a cultura humana perpassa por toda existência dos sujeitos. A pedagogia do "aprender a aprender", que teve início no Brasil há pouco mais de um século, corrobora para preparar os educandos a encaminhar e projetar seu processo de aprendizagem posterior ao ambiente escolar, por todo o percurso de vida.

8 Posteriormente ao modelo da Escola Nova, outras formas de pensar e planejar a educação e a escola vieram a se manifestar até se inserir uma nova versão do "aprender a aprender". Ver sobre em Saviani $(2012,2013)$. 
Neste sentido, Souza (2017, p. 77) evidencia que a educação ao longo da vida resulta em um "[...] desenvolvimento ou formação da competência, da capacidade de aprender a aprender, uma vez que o mundo muda rapidamente e os conhecimentos também". Para o referido autor, as mudanças sociais demandam um processo de adequação dos indivíduos que, para tal, necessitam desenvolver em si uma capacidade de compreender a realidade para apreendê-la.

A pedagogia do "aprender a aprender" contribui para que os sujeitos iniciem seu processo de aprender a apropriar-se do mundo da cultura no ambiente escolar e, a posteriori, sigam este processo ao término da escolarização.

A conclusão é que a educação não é um processo que se dá apenas no ambiente escolar e durante o percurso escolar do sujeito, ela deve ocorrer ao longo de toda a vida do indivíduo, cabendo à escola a função de preparar o aluno para que ele possa aprender ao longo de toda sua vida, de toda sua passagem por este lado do mistério. (idem, ibidem)

Após caracterizarmos e situarmos, de modo amplo, a pedagogia do "aprender a aprender" em sua versão da Escola Nova, o que nos convém é entendermos como esta se manifesta atualmente, considerando o movimento histórico das mudanças sócias, políticas, econômicas que estabeleceram mudanças no sistema educacional a partir de políticas educacionais neoliberais. Encaminhamo-nos para o campo do neo-escolanovismo, compreendendo as novas roupagens do "aprender a aprender" para adequar os sujeitos às demandas do capital.

Encaminhamos nossa trajetória histórica pelo final do século XX, mais precisamente nos anos 1990, período em que assume como chefe de governo brasileiro Fernando Henrique Cardoso, representando um governo de centro-direita que priorizava as ordens da mundialização do capital para construir seu projeto hegemônico. A reforma na estrutura do Estado brasileiro projetada por Fernando Henrique esteve balizada pela doutrina dos mecanismos internacionais, em específico pelo Consenso de Washington, que propiciou uma suscetibilidade do Brasil às ordens do mercado internacional (Frigotto, 2005).

No período supracitado, estava se consolidando no Brasil uma afluência neoliberal provinda do interior das reuniões de Washington e que estava iniciando sua manifestação nos demais países da América Latina. Esta ideologia neoliberal, no entendimento de Apple (2005), proferiu ataques diretos aos serviços públicos a partir de uma reestruturação institucional que assegurava que o Estado deveria curvar-se aos interesses de negócios, tornando os serviços e bens públicos - em especial a educação - mercadorias.

Nesse movimento de mudanças, uma série de reformas para os países da América Latina foram sendo estabelecidas. Saviani (2013b) elucida estas reformas como um:

[...] programa de rigoroso equilíbrio fiscal a ser conseguido por meio de reformas administrativas, trabalhista e previdenciárias tendo como vetor um corte profundo nos gastos públicos. Em segundo lugar, impunha-se uma rígida política monetária visando à estabilização. Em terceiro lugar, a desregulação dos mercados tanto financeiro como do trabalho, privatização radical e abertura comercial. Essas políticas que inicialmente tiveram de ser, de algum modo, impostas pelas agências internacionais de financiamento mediante as chamadas condicionalidades, em seguida perdem o caráter de imposição, pois são assumidas pelas próprias elites econômicas e políticas dos países latino-americanos. (Saviani, 2013b, p 428)

Atualmente no Brasil, no âmbito das reformas de Estado nos campos trabalhista, previdência, da terceirização, educacional ${ }^{9}$ (reformas do Ensino Médio e Base Nacional Comum Curricular), algumas estão em curso de votação e/ou até aprovadas pelo congresso nacional. Isso indica que as reformas impostas ao Estado brasileiro nos mandatos de Fernando Henrique estão sendo pautas consistentes de nossos representantes políticos para atender as ordens da iniciativa privada e do capital internacional para manter a hegemonia do neoliberalismo.

A nova reestruturação sócio-econômica, que minimizou o papel do Estado para possibilitar a mobilidade do mercado, centrou ênfase ao privado, ao particular e ao sujeito. Em virtude disto, o processo educativo passou a receber novas interferências, acarretando uma transferência de responsabilidades na busca pelo conhecimento fundamental para os postos de trabalho. A saber, as responsabilidades pelo processo educativo que estavam atribuídas ao Estado passaram a ser incumbência de cada individuo (idem).

9 Abordado no próximo item. 
Outro elemento relevante que corroborou a priori para consolidar esta reestruturação social e as mudanças no cenário educacional foram as mudanças no mundo do trabalho. A expansão do modo de produção toyotista, projetou um perfil de sujeito-trabalhador autônomo e flexível para se inserir num mercado de trabalho vulnerável e suscetível a drásticas mudanças. Deste modo, os parâmetros educacionais assumiram pretensões produtivistas e empresariais, ressignificando os sentidos do "aprender a aprender" (Frigotto, 2005).

As mudanças no mundo do trabalho e os avanços na complexidade da sociedade, caracterizadas pela dinâmica e instabilidade de relações de produção, estabeleceram uma pedagogia do "aprender a aprender" preocupada com as incertezas da (re)produção do capital (Laval, 2004). O novo sentido do "aprender a aprender" do neo-escolanovismo - que em sua concepção geral é aprender a estudar, aprender a buscar conhecimentos - "[...] liga-se à necessidade de constante atualização exigida pela necessidade de ampliar a esfera da empregabilidade [...]" (Saviani, 2013b, p. 431). Em outras palavras, o processo de escolarização pretende capacitar o educando para aprender por toda vida, porém não caracteriza um processo de aprendizagem na dimensão de atualização de saberes (considerando a provisoriedade do conhecimento). Pelo contrário, é um aprendizado de algo novo a cada momento de mudança e instabilidade sócio-econômica (idem).

Percebemos que as características que distinguem o "aprender a aprender" da Escola Nova em relação ao escolanovismo, é que a primeira versão realizava um processo educativo pautado pelos interesses dos sujeitos que possuíam e cumpriam uma determinada função em benefício do todo. Entretanto, na segunda versão, há uma preocupação em produzir um processo educativo que se enquadra aos ditames do capital na intenção de (re)produzi-lo e fomentar as ordens do mercado, produzindo um perfil de sujeito-trabalhador suscetível à flexibilização e adaptação, pautando uma formação escolar limitada e superficial.

Esta forma de pensar e organizar a educação, que constituiu a nova versão do "aprender a aprender", esteve balizado pelo Relatório Jacques Delors, sistematizado na década de 1990 e publicado em 1996 num documento da UNESCO. A pretensão do relatório foi elucidar linhas orientadoras para a educação mundial no século XXI, materializando a concepção de "educação ao longo da vida" (Delors, 2010, p. 12). As novas formas de conceber a educação, segundo o relatório, se inseriram no contexto brasileiro em 1998 compondo as bases teóricas para elaborar as políticas educacionais expostas por meio dos Parâmetros Curriculares Nacionais (Saviani, 2013b, p. 433).

Estas políticas educacionais foram se consolidando no cenário escolar brasileiro na forma de caminhos para concretizar as metas e interesses do capital a partir da formação de capital humano para o mercado. Tais leis se expandiram no decorrer dos anos e se expressam atualmente em outras reformas. Vejamos na sequencia qual é a (nova) conjuntura destas politicas educacionais expressadas pela Reforma do Ensino Médio no Estado do Rio Grande do Sul.

\section{“APRENDER A APRENDER" PARA QUÊ? AS REFORMAS EDUCACIONAIS EM QUESTÃO!}

Ao mesmo momento em que foi aprovada a Lei 9.394/96, foi realizado um estudo sob a autorização da UNESCO com o título "Educação: um tesouro a descobrir", também visto como "Relatório Jacques Delors". O livro teve sua publicação feita no Brasil no ano de 1998 - mesmo ano de publicação dos Parâmetros Curriculares Nacionais (PCN's/1997)para o ensino fundamental e um ano antes da publicação dos PCN's para o ensino médio. Apresentado à época pelo ministro da Educação, Paulo Renato afirmou estar convicto da contribuição do Relatório "para o processo em que de modo especial, se empenha o Ministério da Educação, qual seja, o de repensar a educação brasileira" (Delors, 2001, p. 10).

O relatório, então, implementou numa das primordiais apreciaçõesaconstrução dos PCN's da educação básica brasileira. Umdos princípios que estão no relatório e que tangenciam os PCN's, podemos destacar os intitulados pilares da educação, que são eles, aprender a aprender, aprender a fazer, aprender a conviver e aprender a ser. Em detrimento a filiação teórica, o lema dos PCN's para a reforma da educação básica brasileira ficou famoso como aprender a aprender. Slogan esse que faz alusão diretamente, de acordo com Saviani (2007), ao eixo das ideias pedagógicas da escola nova. Podemos justificar essa relação

[...] deslocando o eixo do processo educativo do aspecto lógico para o psicológico; dos conteúdos para os métodos; do professor para o aluno; do esforço para o interesse; da disciplina para a espontaneidade, configu- 
rou-se uma teoria pedagógica em que o mais importante não é ensinar e nem mesmo aprender algo, isto é, assimilar determinados conhecimentos. O mais importante é aprender a aprender, isto é, aprender a estudar, a buscar conhecimentos, a lidar com situações novas. E o papel do professor deixa de ser o daquele que ensina para ser o de auxiliar o aluno em seu próprio processo de aprendizagem[...] (Saviani, 2007, p. 429).

Acredito na pertinência da pergunta, então, aprender a aprender para quê? Possivelmente a resposta nos apontaria à ideia de que no atual processo do acumulo do capital, importaria mais ao aluno gerar competências para, a cada dia se preciso fosse aprender novas situações que lhe permitiriam se manter interligado ao processo produtivo que se deve exercer no capital. Esquivar-se dessa situação não é serviço fácil nem mesmo a quem dela tem compreensão. De tal modo, que na atualidade, é preciso reconhecer a ascendência do neopragmatismo, que, não bastasse serprática pedagógica decorrente em muitas instituições de ensino que formam para o mercado de trabalho, passa a modelar legalmente e fundamentar a reforma do ensino médio pela finalidade de desenvolver nos alunos, competências e habilidades que lhes permitam continuar aprendendo, de modo a ser capaz de se adequar com flexibilidade a novas condições de ocupação ou melhoramentos posteriores, conforme a necessidade do processo produtivo. A relação entre o lema aprender a aprender e pedagogia das competências é sintetizada da seguinte maneira por Saviani:

a "pedagogia das competências" apresenta-se como outra face da "pedagogia do aprender a aprender", cujo objetivo é dotar os indivíduos de comportamentos flexíveis que lhes permitam ajustar-se às condições de uma sociedade em que as próprias necessidades de sobrevivência não estão garantidas. Sua satisfação deixou de ser um compromisso coletivo, ficando sob a responsabilidade dos próprios sujeitos, que segundo a raiz etimológica dessa palavra, se encontram subjugados à "mão invisível do mercado" (Saviani, 2007, p. 435).

A atual reforma do Ensino Médio expressa na Lei 13.415 de 16.2.2017 promoveu alterações radicais na proposta da Lei de Diretrizes e Bases (LDB/96).ALei 13.415, decorrente de uma Medida Provisória (MP746/2016), criticada já a partir da sua origem autoritária, a qual teve inúmeras manifestações contrarias a sua implementação, havendo ocupações de escolas públicas do pais todo durante o ano de 2016, por parte dos alunos que ali se encontravam matriculados. Manifestações que foram dirigidas tanto a forma quanto ao conteúdo da política educacional proposto pela reforma.

A apresentação da reforma por meio da medida provisória sugere, aos que pouco acompanham as discussões em torno da educação nacional, que se pautou através de ação intempestiva do então governo vigente. Também vale ressaltar que a MP 746 que instituiu, em um primeiro momento, a reforma do ensino médio constituiu-se na segunda medida de impacto adotada pelo então governo em exercício. A primeira, provem da Proposta de Emenda Constitucional (PEC) 241, que posteriormente veio a ser o Projeto de Lei (PL) 55/2016 e, por fim na PEC 95, por consequência da qual foi instituído o Novo Regime Fiscal que estabeleceu restrições severas as despesas primarias do nosso pais por vinte anos, a partir do na de 2017.

Nos referidos documentos da reforma do ensino médio há muitas citações em volta do trabalho e da cidadania como cernes imprescindíveis ao trabalho pedagógico.Contudo, apreciando tanto uso da polissemia quanto o uso de palavras historicamente situadas, Ramos (2007) nos adverte acerca do sentido das mesmas na reforma. Podemos expressar o trabalho com uma gama de sentidos, porem ele é problematizado pela autora a partir de dois polos: trabalho como contexto social versus trabalho como princípio educativo; trabalho como mediação versus trabalho como fim; trabalho como práxis produtiva versus trabalho como práxis humana. $\mathrm{O}$ trabalho, segundo a autora, aparece na reforma como contexto social, predominantemente. Como um fim a que todo o processo deve se submeter e, portanto, como práxis produtiva.

A crítica não pode ser refutada porque a atitude em considerar o trabalho como princípio educativo como mediação e práxis humana, implicaria numa reforma no mínimo contra-hegemônica, isto é, implicaria em uma concepção de homem omnilateral, de educação emancipadora e de uma sociedade socialista. Desse modo, quando o trabalho aparece como princípio, é educativo apenas pela ótica do capital, isto é, como trabalho assalariado, e não como ação por meio da qual o homem transforma a natureza e se relaciona com os outros homens para a produção de sua própria existência, portanto, como categoria ontológica da práxis humana. A concepção de trabalho submetido aos interesses da acumulação capitalista também nos indica a concepção de cidadania presente nos documentos da reforma do ensino médio.

Diante da instabilidade contemporânea, a cidadania não é resgatada como valor universal, mas como a cidadania possível, conquistada de acordo com o alcance dos próprios projetos individuais e segundo os valores que 
permitam uma sociabilidade pacífica e adequada aos padrões produtivos e culturais contemporâneos (Ramos, 2007, p. 140)

A partir deste contexto, podemos também elencar as mudanças circunstanciais que a reforma do ensino médio traz em detrimento a Lei de Diretrizes e Bases (LDB/96), mudanças essas que alteram totalmente as concepções acerca de pontos que pareciam estar fechados, como podemos ver no quadro a seguir:

\section{Principais Pontos Alterados pela Lei $\mathrm{n}^{\circ} \mathbf{1 3 . 4 1 5 / 1 7}$}

É pertinente relacionar os principais pontos da Lei $\mathrm{n}^{\circ}$ 9.394, de 20 de dezembro de 1996 que serão alterados pela Lei n 13.415 de 16/02/2017.

Quadro 1 - O que muda na LDB

\begin{tabular}{|c|c|c|}
\hline Pontos & Antes & Depois \\
\hline Carga Horária & $\begin{array}{l}\text { A LDB prevê que, nos três anos do ensino } \\
\text { médio, os alunos tenham no minimo } 800 \\
\text { horas de aula, e que cada ano tenha pelo } \\
\text { menos } 200 \text { dias letivos. }\end{array}$ & $\begin{array}{l}\text { A Lei } n^{\circ} 13.415 / 17 \text { do governo federal amplia } \\
\text { "progressivamente" a carga horária para } 1.400 \\
\text { horas, sem especificar um número minimo de } \\
\text { dias letivos por ano nem um prazo para a } \\
\text { ampliação. }\end{array}$ \\
\hline $\begin{array}{l}\text { Disciplinas } \\
\text { Obrigatórias }\end{array}$ & $\begin{array}{l}\text { O ensino de artes e de educação física era } \\
\text { obrigatório na educação básica, incluindo no } \\
\text { ensino médio. Desde 2008, aulas de } \\
\text { filosofia e sociologia também eram } \\
\text { obrigatórias nos três anos. }\end{array}$ & $\begin{array}{l}\text { A partir de agora, a decisão de incluir artes, } \\
\text { educação física, filosofia e Sociologia nas } \\
\text { aulas do ensino médio dependerá do que será } \\
\text { estipulado pela Base Nacional Comum } \\
\text { Curricular. }\end{array}$ \\
\hline $\begin{array}{l}\text { Ensino } \\
\text { Técnico }\end{array}$ & $\begin{array}{l}\text { A lei já previa a possibilidade de as escolas } \\
\text { integrarem o ensino técnico e } \\
\text { profissionalizante ao ensino médio em } \\
\text { diversos modelos. }\end{array}$ & $\begin{array}{l}\text { A formação técnica e profissional passa a ter } \\
\text { peso semelhante às quatro áreas do } \\
\text { conhecimento. A mudança também inclui a } \\
\text { possibilidade de "experiência prática de } \\
\text { trabalho no setor produtivo" ao aluno. }\end{array}$ \\
\hline $\begin{array}{c}\text { Lingua } \\
\text { Estrangeira }\end{array}$ & $\begin{array}{l}\text { As escolas eram obrigadas oferecer, a partir } \\
\text { do sexto ano, aula de pelo menos uma } \\
\text { lingua estrangeira, mas tinham a liberdade } \\
\text { de escolher qual lingua. }\end{array}$ & $\begin{array}{l}\text { O inglês passa a ser a lingua estrangeira } \\
\text { obrigatória em todas as escolas. As escolas } \\
\text { podem oferecer uma segunda lingua, que deve } \\
\text { ser, preferencialmente, o espanhol. }\end{array}$ \\
\hline Professores & $\begin{array}{l}\text { A lei exigia que os professores fossem } \\
\text { trabalhadores de educação com diploma } \\
\text { técnico ou superior "em área pedagógica ou } \\
\text { afim". }\end{array}$ & $\begin{array}{l}\text { Fica permitido que as redes de ensino e } \\
\text { escolas contratem "profissionais de notório } \\
\text { saber" para dar aulas "afins a sua formação". }\end{array}$ \\
\hline Vestibulares & $\begin{array}{l}\text { As universidades são livres para definir que } \\
\text { conteủdos que exigem das provas para } \\
\text { selecionar os calouros, levando em } \\
\text { consideração o impacto da exigência no } \\
\text { ensino médio. }\end{array}$ & $\begin{array}{l}\text { A lei determina que o Conteúdo dos } \\
\text { Vestibulares seja apenas "as Competências, as } \\
\text { habilidades e as expectativas de aprendizagem } \\
\text { das áreas de Conhecimento definidas na } \\
\text { BNCC". }\end{array}$ \\
\hline
\end{tabular}

Fonte: André, V. apud Rodrigues (2016).

Algumas das mudanças previstas pela Lei no 13.415/17 foram logo causando desconforto, não apenas entre os profissionais e estudiosos da área da Educação, como ao mesmo tempo, entre os próprios estudantes, o carro chefe dos afetados pelas alterações provenientes da reforma do ensino médio. Para os opositores da reforma, constam problemas em inumeros pontos da Lei, entretanto, são duas as principais polêmicas: a parte que trata das disciplinas obrigatórias e também a parte que trata do notório saber. (Fajardo, 2017, 
texto digital). No que se trata a respeito às disciplinas que são obrigatórias, não havia uma legislação que concluísse claramente quais eram as matérias que deveriam obrigatoriamente estar compostasno currículo escolar. A LDB mencionava em diferentes partes de seu texto as disciplinas de Português, Matemática, Artes, Educação Física, Filosofia e Sociologia como obrigatórias nos três anos do ensino médio.

A polêmica se apresentou quando a MP n 746 colocou como obrigatórias apenas as disciplinas de Português e Matemática, o que não agradou nem um pouco vários envolvidos com Educação, especialmente professores e estudantes. Entretanto, o texto final da Lei no 13.415/17:

[...] reinclui como disciplinas obrigatórias Artes e Educação Física, que tinham sido excluídas pelo texto original da MP. Entre as línguas estrangeiras, o Espanhol não será mais obrigatório, ao contrário do Inglês, que continua obrigatório a partir do $6^{\circ}$ ano do ensino fundamental. Já as disciplinas de Filosofia e Sociologia, que tinham sido excluídas pelo Poder Executivo, passarão a ser obrigatórias apenas na BNCC, assim como Educação Física e Artes (Sancionada, 2017, texto digital).

Em outro ponto, o da questão do notório saber, referente ao Art. $6^{\circ}$ da Lei no 13.415/17, que altera o Art. 61 da Lei no 9.394/96. A priori, o texto da MP no 746 trazia a imediata redação: "IV - profissionais com notório saber reconhecido pelos respectivos sistemas de ensino para ministrar conteúdos de áreas afins à sua formação para atender o disposto no inciso V do caput do art. 36". Conforme os especialistas, essa redação permitia "que profissionais sem licenciatura possam lecionar disciplinas técnicas profissionalizantes" (EMPREGO, 2017, texto digital).

\section{CONSIDERAÇÕES FINAIS}

Ponderamos, em virtude do exposto acima, que não há neutralidade dentro da produção do conhecimento, dado que envolve a influência mutua entre o material dos homens e a atividade da consciência que se determina a partir da motivação do sujeito em afinidade à presença histórica do objeto. Em decorrência, a análise da relação entre asuperestrutura e a base econômica é essencial para a compreensão do estilo de produção e sua articulação com as formas de consciência social.

A partir disso não é possível considerar que os problemas da formação humana pela via escolar possam ser efetivamente resolvidos apenas por alterações nas políticas educativas no que se faz referência ao currículo, aos métodos, à formação, pois a educação traz limites, considerando especialmente o papel que muitas vezes desempenhamos como mera reprodução social. É necessário, então, entendê-la, também, como área de contrassensos e, portanto, como campo de possibilidades de modificação, pelo menos no campo cultural (em sentido amplo).

Nessa definição é necessário que o estudo das políticas educacionais analise o papel da ideologia, entendida como forma especifica de consciência social, materialmente ancorada e sustentada, e não de forma distorcida da realidade. Assim sendo, sua abrangência efetiva depende da apreensão da lógica global de um determinado sistema de produção, pois essa tende a implicar nas políticas educacionais para que vá de encontro com a reprodução do sistema que o permeia.Com isso podemos ver que não basta apenas a defesa da perspectiva de educação democrática e participativa com vistas à formação cidadã (emancipação política), como propõe a contrarreforma do Ensino Médio. Há necessidade de uma educação que proponha, além disso, a emancipação humana.

Por fim, ponderamos que o processo de aprendizagem e apropriação da cultura que compõe os saberes escolares, abordados a partir da atual versão da Pedagogia do "aprender a aprender" e manifestado pelas políticas e reformas educacionais, seguindo as mudanças sócio-econômicas neoliberais, corrobora para formar sujeitos-trabalhadores em nível superficial e limitado de conhecimento, tratados como instrumento para (re)produzir o capital. Retomando o exposto da introdução, não nascemos prontos, mas também dispomos do direito de uma educação que nos humanize de forma crítica e emancipada, para desvelarmos os fenômenos e contradições da realidade e não para servirmos deobjeto para o capital financeiro, mas de sujeitos construtores de nossa existência. 


\section{REFERÊNCIAS}

Apple, M. W. Para além da lógica do mercado: compreendendo e opondo-se ao neoliberalismo. Tradução de Gilka Leite Garcia, Luciana Ache. RJ: 2005.

Brasil. Ministério da Educação. Secretaria de Educação Média e Tecnológica. PCN + Ensino Médio: Orientações Educacionais Complementares aos Parâmetros Curriculares Nacionais. Brasília: MEC/SEMTEC, 2002.

Brasil. Ministério da Educação. Conselho Nacional de Educação. Diretrizes Curriculares Nacionais para o Ensino Médio. Parecer CEB n 3, 26 de junho de 1998.

Brasil. MP 746, de 22 de setembro de 2016. Institui a Política de Fomento à Implementação de Escolas de Ensino Médio em Tempo Integral, altera a Lei no 9.394, de 20 de dezembro de 1996, que estabelece as diretrizes e bases da educação nacional, e a Lei no 11.494 de 20 de junho 2007, que regulamenta o Fundo de Manutenção e Desenvolvimento da Educação Básica e de Valorização dos Profissionais da Educação, e dá outras providências. Brasília, set. 2016. Disponível em:https://www2.camara.leg.br/legin/fed/medpro/2016/medidaprovisoria-746-22-setembro2016-783654-publicacaooriginal-151123-pe.html . Acesso em: 29 mar. 2019.

Brasil. Emprego de professores com notório saber no ensino médio divide senadores. Senado. [S.I.], 12 abr. 2017. Disponível em: https://www12.senado.leg.br/noticias/audios/2017/02/emprego-de-professores-com-notorio-saberno-ensino-medio-divide-senadores . Acesso em: 29 mar. 2019.

Brasil. Lei no 13.415, de 16 de fevereiro de 2017. Altera as Leis nos 9.394, de 20 de dezembro de 1996, que estabelece as diretrizes e bases da educação nacional, e 11.494, de 20 de junho 2007, que regulamenta o Fundo de Manutenção e Desenvolvimento da Educação Básica e de Valorização dos Profissionais da Educação, a Consolidação das Leis do Trabalho - CLT, aprovada pelo Decreto-Lei no 5.452, de 1 o de maio de 1943, e o Decreto-Lei no 236, de 28 de fevereiro de 1967; revoga a Lei no 11.161, de 5 de agosto de 2005; e institui a Política de Fomento à Implementação de Escolas de Ensino Médio em Tempo Integral. Brasília, fev. 2017. Disponível em:http://www.planalto.gov.br/ccivil 03/ Ato2015-2018/2017/Lei/L13415.htm. Acesso em: 29 mar. 2019

Brasil. Senado Federal. Comissão Mista da MP 746/2016. Parecer 95/2016 do Senador Pedro Chaves sobre Projeto de Conversão da MP 746 em Lei. Brasília, nov. 2016.

Cortella, M. S. Não nascemos prontos! : provocações filosóficas. 19. Ed. -Petropolis, RJ: Vozes, 2015.

Delors, J. Educação: um tesouro a descobrir. São Paulo: Cortez, Brasília; DF: MEC: UNESCO, 2001.

Delors, J. Educação, um tesouro a descobrir: relatório para UNESCO da comissão Internacional sobre Educação para o século XXI. Brasília: Faber-Castell, 2010.

Fajardo, V. Entenda a reforma do ensino médio. G1. Rio de Janeiro, 15 mar. 2017.

Frigotto, G. A produtividade da escola improdutiva: um (re)exame das relações entre educação e estrutura econômico-social capitalista. 9 ed. São Paulo: Cortez, 2010a.

Frigotto, G. Escola pública brasileira na atualidade: lições da história. In J. Lombardi; D. Saviani; M. Nascimento (orgs). A escola pública no Brasil: história e historiografia. Campinas, SP: Autores Associados, 2005.

Gil, A. C. Métodos e técnicas de pesquisa social. 6 ed. São Paulo: Atlas, 2008.

Laval, C. A Escola não é uma empresa. O neo-liberalismo em ataque ao ensino público. Londrina: Editora Planta, 2004.

Rodrigues, Mateus. Governo lança reforma do ensino médio; veja destaques. G1. Rio de Janeiro, 25 out. 2016. Disponível em: https://g1.globo.com/educacao/noticia/temer-apresenta-medida-provisoria-da-reforma-do-ensinomedio-veja-destaques.ghtml. Acesso em: 29mar. 2019.

Ramos, Marise Nogueira. Pedagogia das competências: autonomia ou adaptação? São Paulo: Cortez, 2002.

Ramos, M. Pedagogia das competências: autonomia ou adaptação?. São Paulo: Cortez Editora, 2001.

Ramos, M. A pedagogia das competências: autonomia ou adaptação?. 3ed. São Paulo: Cortez, 2007.

Saviani, D. Escola e Democracia. 42ªed. Campinas, SP: Autores Associados, 2012.

Saviani, D. O neoprodutivismo e suas variantes: neo-escolanovismo, neoconstrutivismo, neotecnicismo (1991-2001). In: D. Saviani. História das idéias pedagógicas no Brasil. Campinas: Autores associados, 2007.

Saviani, D. Pedagogia histórico-crítica: primeiras aproximações. 11 ed. Campinas, SP: Autores Associados, $2013 a$.

Saviani, D. História das ideias pedagógicas no Brasil. 4ed. Campinas, SP: Autores Associados, $2013 \mathrm{~b}$. 
Souza, G. Inimigos públicos: ensaios sobre a mercantilização da educação no Brasil. 1ed. São Paulo: Usina Editora, 2017.

Sancionada Lei da Reforma no Ensino Médio. Senado. [S.I.], 17 fev. 2017. Disponível em: Acesso em: 29 mar. 2019.

Fecha de Recepción: 01/04/2019

Fecha de Aceptación: 07/11/2019 